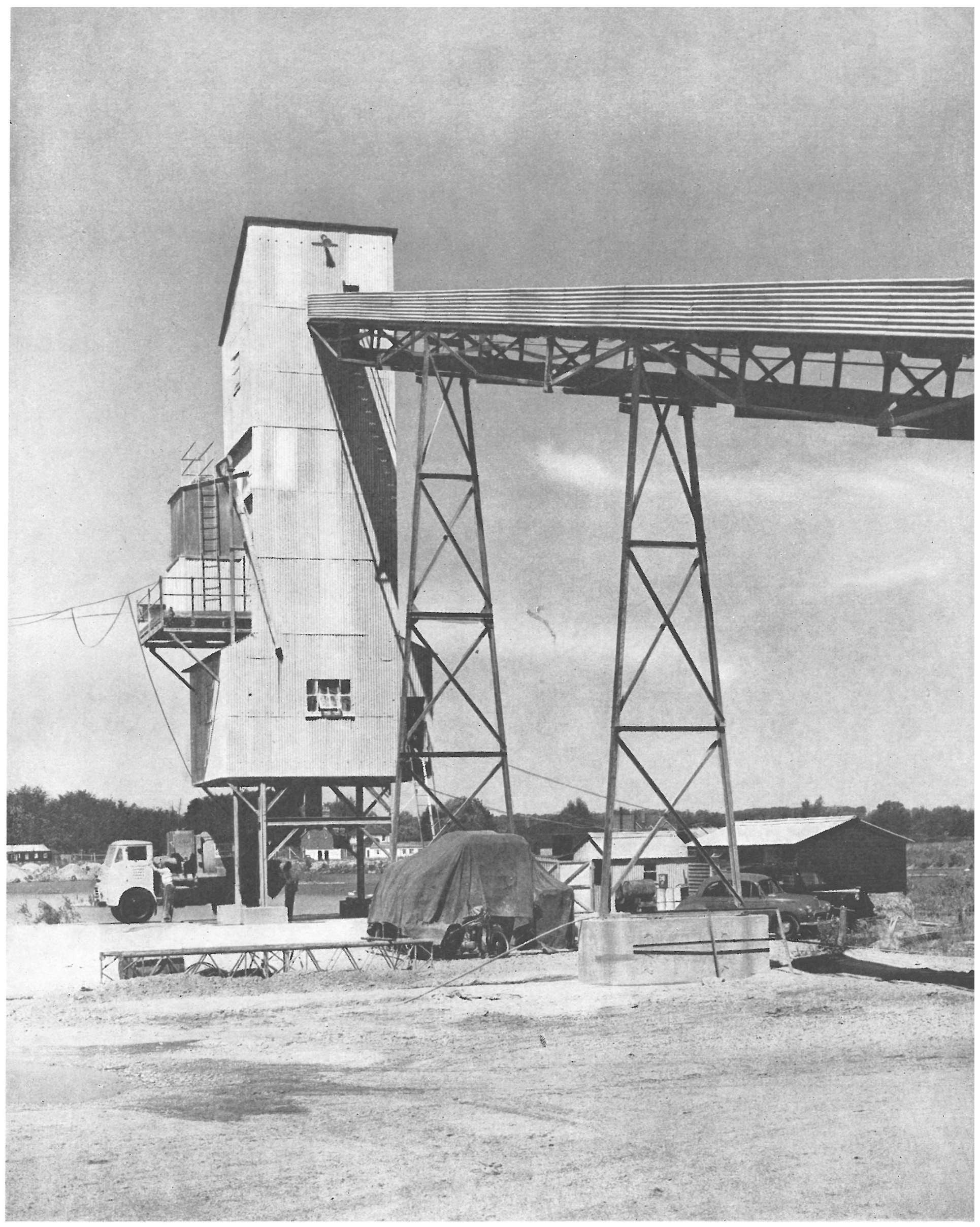

Información amablemente facilitada por la casa F'rederick Parker Ltd., de Leicester (Inglaterra)

\title{
central hormigonera Parker
}




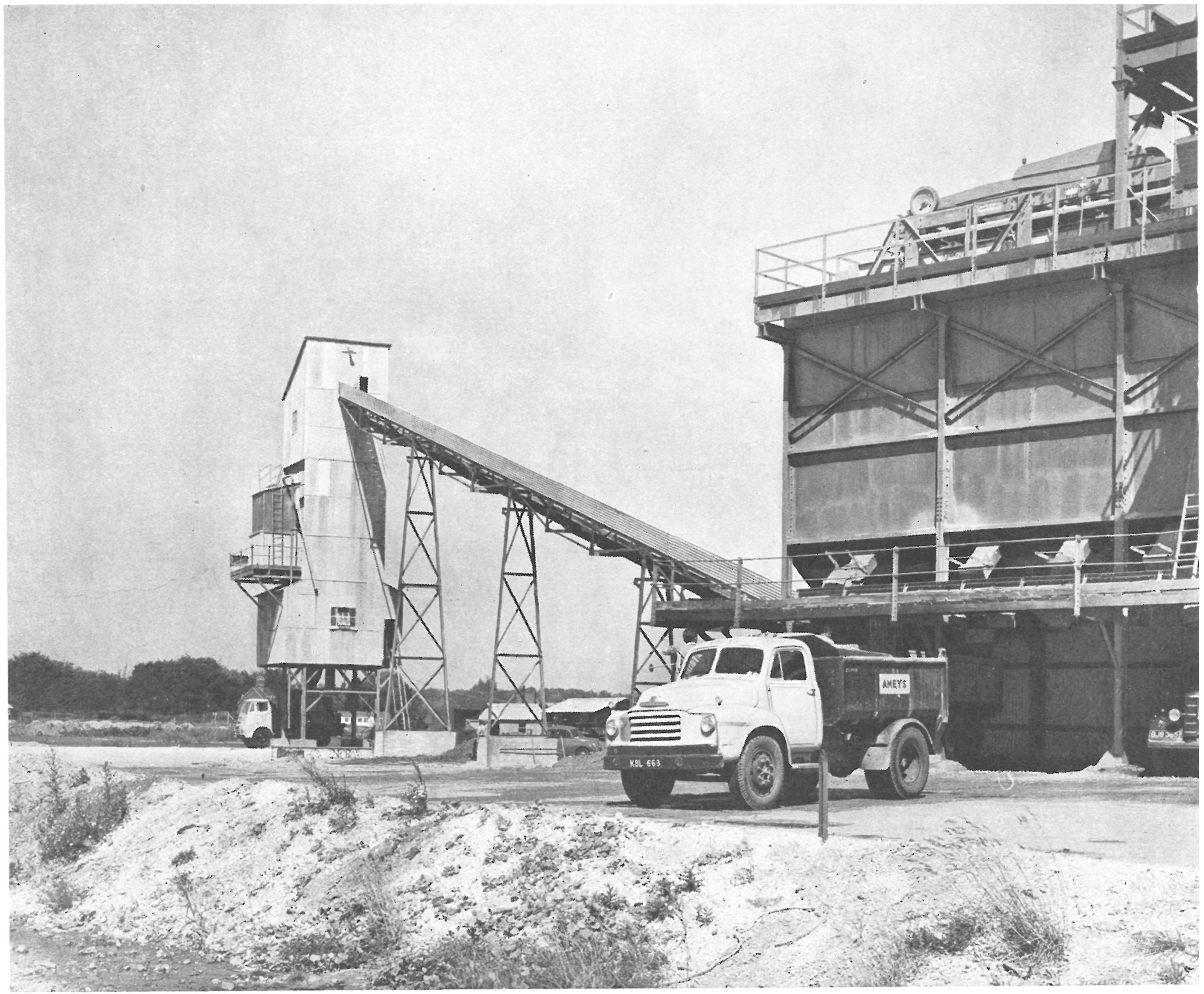

$864 \cdot 7$

\section{La instalación}

En general, la instalación de una central hormigonera es siempre función del lugar elegido para su ubicación en obra, algunas veces alejada de la misma y otras explotada regularmente para poner el hormigón en el mercado como si se tratase de un material cualquiera.

En este tipo de centrales, la instalación se extiende en altura. La central propiamente dicha constituye una torre, y el almacenado de áridos constituye un anexo de la central. Los áridos se pueden depositar en recipientes, sobre cuyas tolvas vierten los volquetes que lo transportan, o bien en montones, debajo de los cuales se ha preparado previamente un túnel, dentro del cual corre una cinta transportadora. Tanto en un sistema como en el otro, la alimentación final de la central se hace con una cinta que recoge los áridos de los recipientes o del túnel y los eleva a los pequeños depósitos de la parte superior de la torre de la central, de donde van descendiendo por gravedad hasta la hormigonera o la mezcladora en seco cuando la central se explota con camiones de cuba hormigonera.

\section{La central}

La central Parker, de dosificación gravimétrica, está constituída por una serie de depósitos superiores, de 4 a 6 , en los que se depositan los áridos procedentes de la cinła alimentadora por medio de una canaleta que gira alrededor del eje de una tolva. 


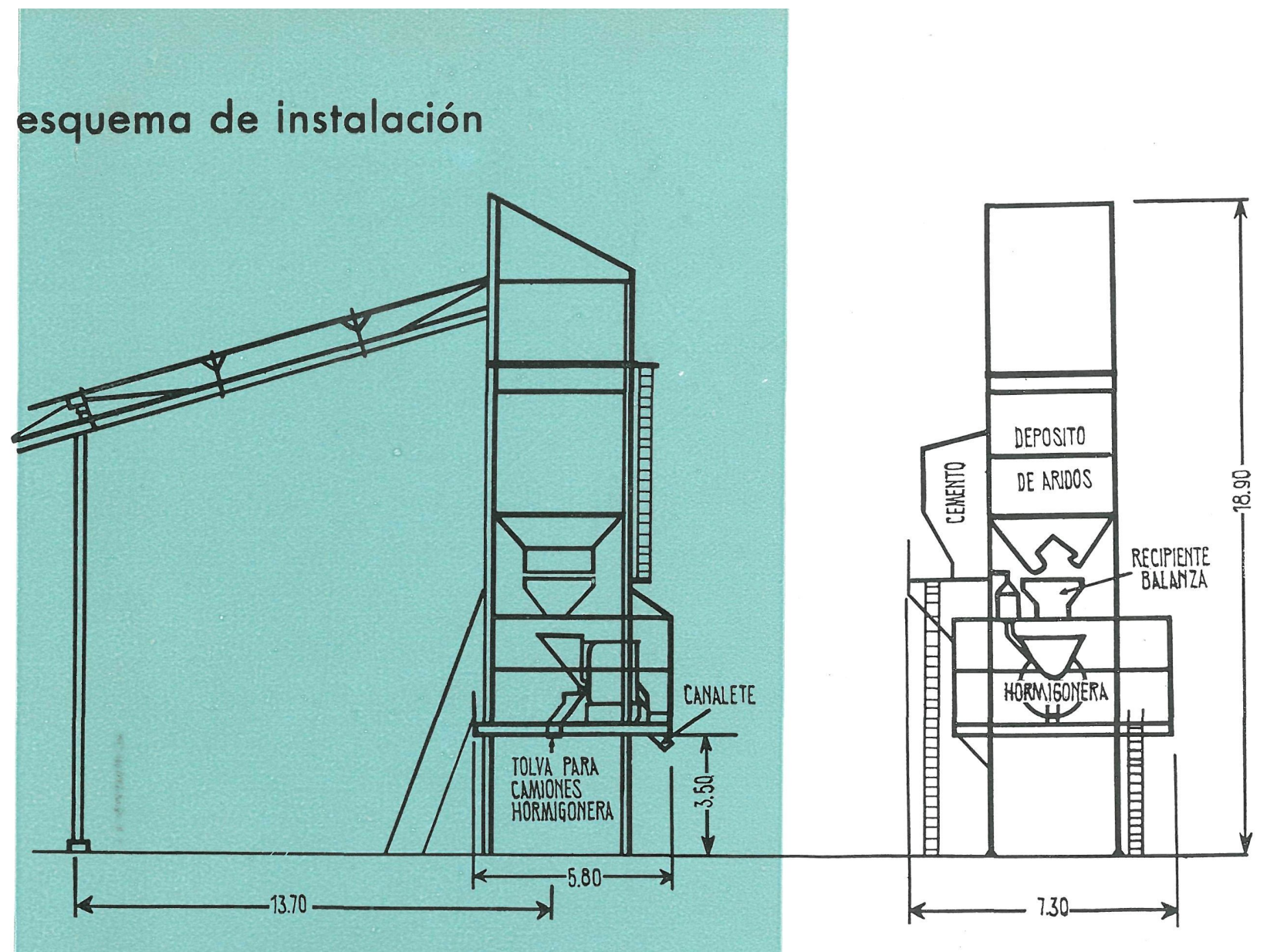

De estos depósitos, provistos de compuertas de sector, se llevan los áridos al compartimiento balanza o de pesada, que se halla debajo. El peso de la mezcla se va registrando en un sector graduado situado en el cuadro de mando. El cemento, depositado en un recipiente particular, montado en la torre, se transporta a este depósito mediante una elevadora en espiral movida eléctricamente. Su peso también se registra en el sector del cuadro de mandos.

Terminada y pesada la mezcla, aún en seco, ésta se puede dirigir a la hormigonera o a los camiones hormigonera que la han de transportar. Cuando la mezcla es húmeda, el agua se regula y controla convenientemente a partir de un depósito también instalado en la torre de la central. 


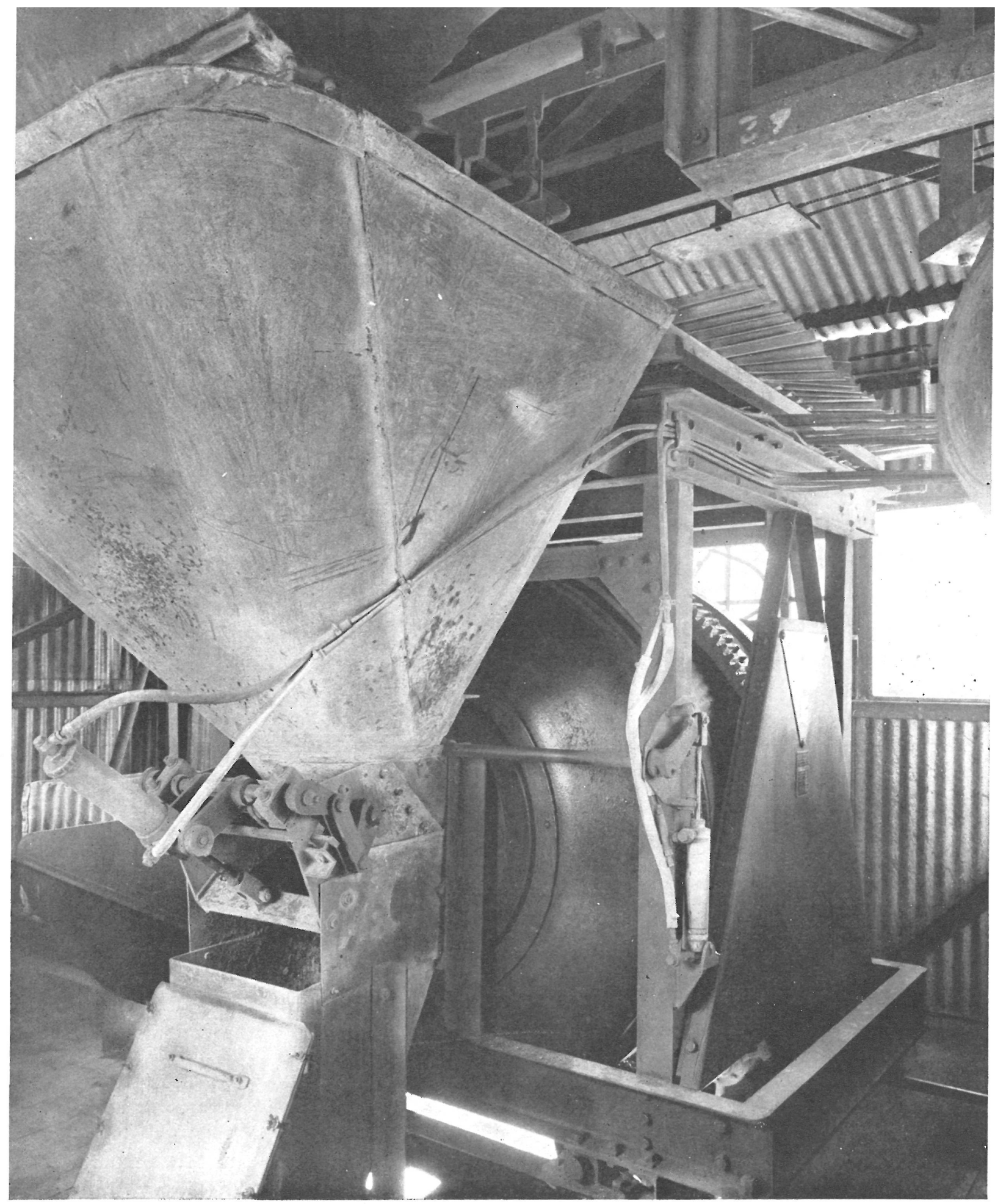

Fotos: LESLIE J. GROVES

Todas las operaciones de la central se realizan con una instalación de aire comprimido. Los mecanismos de cierre y apertura de compuertas se efectúan valiéndose de pulsadores instalados en la cabina de mando, de donde se regulan todas estas operaciones. Esto no obstante, todas estas maniobras se pueden realizar manualmente y a voluntad. Para el suministro de aire comprimido se dispone de un grupo motocompresor y un recipiente de cabida adecuada que regula la presión.

\section{El cemento}

Este material se puede depositar en un silo cuando se suministra a granel, en cuyo caso el paso del silo al pequeño depósito de servicio instalado en la torre se lleva a cabo mediante una serie de tubos aspirantes.

J. J. U. 